\title{
DEPDC1/MPHOSH1 Peptide Vaccine
}

National Cancer Institute

\section{Source}

National Cancer Institute. DEPDC1/MPHOSH1 Peptide Vaccine. NCI Thesaurus. Code C74023.

A cancer vaccine containing HLA-A*2402-restricted epitopes derived from DEP domain containing 1 (DEPDC1) and M phase phosphoprotein 1 (MPHOSPH1) with potential immunostimulatory and antineoplastic activities. Upon administration, DEPDC1/MPHOSH1 peptide vaccine may elicit a specific cytotoxic T lymphocyte (CTL) response against tumor cells expressing DEPDC1 and MPHOSPH1, tumor antigens that are overexpressed in bladder cancer cells. 